\title{
TEO-SEKSOLOGI SEBAGAI BAGIAN DARI KONSEP UPACARA PENCIPTAAN KETURUNAN DALAM PUSTAKA SUCI BṚHAD'ARANYAKA UPANIṢAD BRĀHMAṆA KEEMPAT
}

\author{
Oleh: I Ketut Donder
}

\section{ABSTRACT}

Sexual activity is a natural-spiritual activity, that means sexual activity is present on earth because of the will of the Creator. Although sexual activity is present because of the will of the Creator, but its activity is determined as yajna or sacrifice, therefore the age of a person may also engage in sexual activity. When, where can someone do it? In addition, the quantity of sexual activity is determined to achieve the quality of sexual activity as yajna or sacred offerings to the Creator.

Along with the chaos process as part of the process of destruction of the universe as a recycling of the universe as described in Yuga's theory; the quality of sexual activity is also increasingly chaotic. In recent years, sexual activity has become a platform for gourmand festivals or an exhibition of genitals or genital tournaments as can be seen on youtube electronic media. Men and women compete with sex forces, this reality will give birth to more and more giant humans, and humans will experience destruction. Therefore the generation of melinial as a digital generation must save itself from the process of destruction from the reality of the negative effects of increasingly chaotic sexual activity.

\section{PENDAHULUAN}

Latar Belakang

Seksologi perlu diberikan untuk memahami bahwa hubungan seksual ditetapkan oleh pustaka suci bukan hanya untuk kepuasan nafsu seksual, tetapi untuk menurunkan keturuan atau untuk kelangsungan hidup generasi manusia, terutama untuk melahirkan putra-putri yang baik atau suputra dan suptrika. Terdapat berbagai pandangan yang saling antagonis dalam memandang seks, hubungan seks atau seksualitas. Sebagai realitas yang tidak lain adalah rtam atau hokum alamiah, maka harus dipandang bukan hanya dari sudut negative belaka. Dunia material ini terbangun dari dua hal yang selalu berlawanan tetapi senantiasa berpasangan sebagai oposisi biner dalam istilah Bali disebut rwabhineda. Sebagaimana pasangan oposisi biner berikut ini, yaitu: atasbawah, kiri-kanan, timur-barat, utara-selatan, manis-pahit, hitam-putih, tua-muda, priawanita, dan sebagainya; keduanya tidak dapat saling meniadakan. Termasuk pandangan oposisi biner dalam cara pandangan melihat seks dan hubungan seks. Ada kelompok yang memandang seks sebagai hal yang menjijikkan da nada kelompok yang mensucikan seks. Pada artikel hasil studi teks atau naskah suci Hindu akan dibahas tentang apa dan bagaiman seks dipandang dalam pustaka Upaniṣad.

Ada banyak banyak pustaka Upaniṣad bauk yang ditulis oleh para penulis atau peneliti 
Upaniṣad, baik sebagai orang suci maupun seorang Hindu atau intelektual akademikus, di antaranya Swami Samvidananda Saraswati (2008) dengan judul Essence of The Upanișad; Swami Gambhirananda (2012) dengan judul Eight Upanişads with the Comentary of Sankaracarya Vol.I,II; kelompok para ahli editor K1. Joshi, O.N. Bimali, dan Bindya Trivedi (2007) denganjudul 112 Upaniṣad(Sanskrit Text, English Translation, An Exhaustive Introduction and Index of Verses); K. Narayanasvami Aiyer berjudul Thirty Minor Upaniûad, Editor Prof. Mandu Khama (2011), dll,

Pada artikel ini dipilih pustaka Upaniṣad karya Prof. S. Radhakrishnan (rpt.2008). Salah satu bait Upaniṣad dinguraikan tentang wanita, sbb: 'Wanita sesungguhnya, Gautama, adalah api. Alat kelaminnya adalah minyaknya; rambutnya, asapnya, vulva-nya nyalanya, ketika seseorang memasukinya, rasa nikmat percikannya; Dalam api ini dewata mempersembahkan air mani. Dari persembahan ini muncullah seorang. Dia hidup selama dia hidup. Kemudian ketika dia meninggal (Brhad'aranyaka Upaniṣad VI.2.13 dalam Radhakrishnan 2008:237). Pada bait Upaniṣad lainnya dinyatakan: 'Wanita sesungguhnya, wahai Gautama, adalah api yajña; dari hal ini alat kelamin adalah ghee-nya, apa yang mengundang nafsu adalah asapnya, pukas (vulva) adalah nyalanya, apa yang dikerjakan di dalam adalah bara-nya dan kenikmatan adalah percikan apinya (Chandogya Upaniṣad V.8.1 dalam Radhakrishnan, 2008:331).

Secara metaporik pustaka Sarasamuscaya juga membahasa tentang hakikat wanita sebagai energi potensial yang menggerakan aktivitas dunia. Diuraikan bahwa wanita menjadi pemicu energi keinginan seks laki-laki untuk melakukan hubungan seksual dengan wanita, hal itu membuat dunia manusia bergerak atau berputar. Jika dianalogkan dengan teori Atom Bhor, maka energi seksualitas wanita adalah bagaikan energi electron yang selalu aktif bergerak pada lintasan orbitnya mengeliling inti atom yang bermuatan positif. Pada salah satu sloka dinyakan bahwa “.... gunanya kekayaan disediakan adalah untuk dinikmati dan disedekahkan; dan kegunaan (fungsi) wanita adalah untuk menjadi istri (dirangkul, dicumbui) dan untuk melanjutkan keturanan baik pria maupun wanita,... (Sarasamuscaya 177). Pada sloka lainnya juga disebutkan bahwa .....di antara sekian banyak yang dirindukan, tidak ada yang menyamai kerinduan pada wanita, bahkan kerinduan tersebut membuat rasa sengsara (Sarasamuscara 424). Hal ini mengingatkan pada nyanyian Obie Mesax (1980-an) yang berjuduk Kisah Kasih di Sekolah hingga ia "malu pada semut yang berbaris di dinding seakan bertanta, sedang apa kamu di sini".

Sloka Sarasamuscaya lainnya menyarakan bahwa apapun yang dikerjakan oleh kaum pria, hal itu karena wanita, sebagaimana dinyatakan: "Adapun mereka yang ingin berdiam di dalam desa, adalah wanita yang menyebabkannya; demikian pula orang yang mau berdagang, adalah wanita pula yang menyebabkannya; pendek kata wanita merupakan sumber energi untuk melakukan apa saja; oleh karenanya, waspadalah kepadanya (Sarasamuscaya 425). Sloka lainnya lagi menyatakan bahwa wanita itu, menyebabkan datangnya cinta, sebab tatap matanya yang berbinar-binar memancarkan energi asmara; bagi orang yang pendek pikiran akan segera terpikat dan terbelenggu; hal itu 
bagaikan jala atau pukat (Sarasamuscaya 427). Dalam hal kemampuan seksual wanita jauh lebih kuat (Sarasamuscaya 432).

Secara esensial wanita dan pria diciptakan sebagai oposisi biner, jika diandaikan wanita itu sebagai bara, maka pria itu sama halnya dengan minyak, karena itu jika seorang pria yang sedang berahi datang mendekat kepada seorang wanita, maka laki-laki pasti akan hancur lebur dan tidak berdaya; sebaliknya jika orang tetap berlaku arif bijaksana, tidak terkuasai hatinya oleh wanita, niscaya ia tetap selalu dalam keadaan selamat (Sarasamuscaya 433). Oleh karena itu, (bagi para siswa atau para mahasiswa brahmacarin dan para pandita) hendaklah dijauhi wanita itu; jangan didengarkan katakatanya, apalagi segala bisik-bisiknya, jangan dipandang wajahnya, apalagi bila ia telanjang bulat karena akan menyebabkan merasuknya nafsu berahi (Sarasamuscaya 441). Sloka-sloka Sarasamuscaya menggambarkan secara objektif bahwa wanita itu sangat besar pengaruhnya terhadap stabilitas kaum pria bahkan dalam sejarah Maha Bharata seorang wanita mampu menumbangkan para ksatria pilih tanding. Selain itu dalam belakangan realitas belakangan, banyak pejabat hancur karena perempuan. Para wanita memiliki potensi yang menyebabkan pria masuk sorga atau masuk neraka, jika seorang lelaki memiliki mental yang baik, maka istrinya akan mengantarnya ke sorga, jika pria memiliki mental yang tidak baik, maka istrinya akan menghantarnya ke neraka. Karena itu, pertemuan apalagi perkawinan lelaki dan perempuan mesti menetapkan tujuan sebelumnya.

Jika perkawinan perkawinan dilandasi hanya oleh nafsu seksual dan bukan dilandasi oleh cita-cita mulia sebagaimana ditetapkan oleh pustaka suci, maka niscaya perkawinan itu tidak akan kekal dan selain itu akan lahir anakanak yang tidak baik pula. Segala perbuatan kedua orangtua akan tercermin pada anakanaknya, sebagaimana pepatah bahasa Indonesia menyatakan: "buah jatuh tidak jauh dari pohon". Karena itu, para generasi melinea sekarang ini jika berharap kelak menjadi para orang tua yang baik dan memiliki putra-putri yang baik, maka satu-satunya jalan adalah belajar pusta agama dan berupaya untuk menerapkannya.

\section{PEMBAHASAN}

\section{II.1 Hubungan Seksual sebagai Kewajiban Suci}

Jayaram menguraikan bahwa tujuan hubungan seksual terutama adalah sebagai tugas (dharma), lalu kesenangan (kama), dan akhirnya pembebasan (moksha). Melalui hubungan seksual setiap orang yang berrumah-tangga diharapkan menghasilkan anak-anak yang baik (suputra) dan memenuhi kewajiban mereka terhadap keluarga, leluhur, dewa, masyarakat, dunia, dan kepada Tuhan itu sendiri. Seseorang dapat meninggalkan dunia, tetapi ia terus hidup dalam putranya yang mewarisi sifat, nama keluarga, identitas, dan pengetahuannya. Melalui swadharma membesarkan anak-anaknya, mendidik mereka, dan membantu mereka menetap dalam kehidupan, ia memastikan kelangsungan keluarganya, dan ketertiban serta keteraturan masyarakat dan dunia.

\section{II.2 Hubungan Seksual sebagai Kurban Suci}

Jayaram menguraikan bahwa referensi untuk hubungan seksual sebagai pengorbanan 
ditemukan dalam Chandogya Upaniṣad (5.8.12) dan Brihadaranyaka Upaniṣad (6.2.13 dan 6.4.2-3). Organ seksual diumpamakan sebagai bagian-bagian tertentu dari sarana pengorbanan, hubungan seksual itu sendiri dibandingkan dengan ritual kurban Vajapeya, yaitu bentuk soma Yajna tertinggi, yang melibatkan perasan jus "Soma" dan dilakukan di musim gugur. Ini disebut 'AtiYajna' karena peringkatnya sama besarnya dengan Rajasuya atau Aswamedha Yajna, yang menuntut tenaga dan sumber daya manusia yang besar. Sementara Rajasuya - upacara penobatan merupakan bagian integral dari sistem politik dan administrasi, memenuhi syarat tentang manfaat penguasa. Ini memberikan interaksi antara penguasa dan yang diperintah. Vajapeya, di sisi lain memiliki tujuan menjaga keharmonisan dengan di negara bagian, dapat dilakukan oleh Kshatriya, seorang Vaisya, Brahman atau orang yang mulia, kaya dan makmur yang mampu mensponsori pengeluaran besar. Yajna ini juga menggabungkan banyak jenis olahraga dan kumpulan cendekiawan dari berbagai bagian negeri untuk bertukar pandangan tentang aspek keagamaan dan sosial. Puncak Yajna ini adalah pemain yang diberi nama "Vajapeyee" dan dipimpin oleh raja sendiri untuk duduk di atas takhta dan dimuliakan dengan mandi berbagai benda suci dan beras (Anna Abhisekha) di bagian penutup. Luarbiasa penghargaan terhadap seks dalam Upanișad yang disamakan dengan upacara yang sangat megah, yaitu Vajapeya.

Selanjutnya, air mani (sperma) diumpamakan sebagai persembahan khusus yang dituangkan ke dalam api di organ seksual wanita. Melalui pengorbanan ini akan muncul janin sebagai buah dari kurban Suci tersebut.
Sloka-sloka Upanișad itu juga menyatakan bahwa pria seharusnya mengetahui esensi hubungan seksual itu sebagai kurban suci. Kalau tidak, jasa kebaikan mereka akan diberikan kepada para wanita. Sebabm tujuan seorang wanita diciptakan adalah untuk melengkapi pria dan mengisi setengahnya, sebagaimana diriwayatkan bahwa pada mulanya Brahman sendirian dan ingin ditemani. Karena itu, Ia menciptakan tubuh-Nya menjadi dua, yaitu pria dan wanita. Karena itu, tubuh manusia dianggap hanya setengah, seperti salah satu dari dua cangkang kacang polong (Br. 1.4.3) atau mata uang logam jaman dulu yang ada lubangnya. Ruang yang dibiarkan kosong diisi oleh istri. Jadi, berdasarkan uraian ini, maka seks memiliki kedudukan suci di dalam ajaran Hindu, sehingga tidak boleh melakukan seks sembarangan, sebab aktivitas seks adalah persembahan suci.

\section{II.3 Pentingnya Energi Seksual Pria}

Jayaram juga menyatakan bahwa Upaniṣad menegaskan kembali keyakinan Veda tentang sifat semen. Dalam kelahiran kembali manusia, semen memainkan peran dominan, sementara sedikit yang disebutkan tentang telur betina. Dalam tubuh laki-laki air mani mewakili bentuk energi tertinggi. Sumbernya adalah makanan. Makanan menjadi air mani setelah bersirkulasi dalam tubuh manusia selama beberapa hari. Karena itu, kehilangan air mani dianggap sama dengan hilangnya energi, terlebih lagi jika orang tersebut adalah selibat atau pertapa. Jiwa menjadi bagian dari air mani hanya melalui makanan. Jalan di mana jiwa-jiwa kembali ke bumi dan melahirkan juga dijelaskan dengan baik. Mereka jatuh ke bumi melalui hujan. Dari bumi mereka memasuki tubuh tumbuhan dan 
hewan. Ketika manusia mengkonsumsinya, mereka menjadi bagian dari air mani di tubuh pria. Dari sana melalui hubungan seksual mereka memasuki rahim. Tidak ada kepentingan seperti itu diberikan pada telur yang diproduksi oleh wanita. Perempuan dianggap sebagai wadah belaka yang memainkan peran pasif dalam kelahiran kembali jiwa, bertindak sebagai wadah belaka untuk menerima air mani dan menampung jiwa-jiwa di dalam rahim mereka sampai mereka dilahirkan.

\section{II.4 Metode dan Adat Istiadat untuk Memfasilitasi Penyatuan Suami-istri}

Jayaram menjelaskan bahwa pada zaman dahulu laki-laki menikmati banyak hak istimewa sosial dan seksual, selain mempraktikkan poligami. Buku-buku hukum Hindu mengakui pernikahan antar suku dengan beberapa ketentuan dan hukum. Wanita juga telah menikmati kebebasan. Upaniṣad berisi mantramantra (Bri.6.4) yang menerangi adat-istiadat seksual pada masa itu. Mereka menggambarkan bagaimana pria harus mendekati wanita untuk melakukan hubungan intim, bagaimana membujuk mereka untuk melakukan hubungan seks, bagaimana cara bercinta, bagaimana cara mengeja mantra. Mereka juga menyarankan solusi untuk memfasilitasi atau mencegah pembuahan, atau untuk memastikan kelahiran seorang putra dengan kualitas dan penyelesaian yang diinginkan. Satu mantram khusus dalam Brihadaranyaka Upanișad berisi informasi tentang ritual rahasia dapat dilakukan oleh suami yang dirugikan terhadap kekasih rahasia istrinya untuk mengambil potensi dan kelebihannya, dan nasib baiknya.

\section{II.5 Cara Mendekati Seorang Wanita untuk Melakukan Hubungan Seksual}

Jayaram menguraikan bahwa meskipun, air mani memainkan peran penting dalam kelahiran kembali jiwa, wanita masih dianggap penting untuk konsepsi mereka. Oleh karena itu, pria harus mencari kerjasama mereka untuk memfasilitasi kelahiran kembali. Mantrammantram (Br. 6.4.6-8) menjelaskan bagaimana melibatkan seorang wanita dan mendekatinya untuk hubungan seksual. Seks konsensual adalah norma. Namun, tampaknya pria memiliki hak untuk menggunakan kekerasan melalui mantra jika para wanita menolak bekerja sama:

1. Sekarang, jika dia melihat bayangannya sendiri di dalam air, dia harus melafalkan nyanyian pujian, "Tambang adalah kilau air mani, ketenaran, kekayaan, dan hasil dari pekerjaan baik." Memang, ada keindahan pada wanita ketika mereka membuang pakaian yang tidak murni (yang dipakai saat menstruasi). Karena itu, ketika dia telah melepas pakaiannya yang tidak murni dan bersinar dengan semangat, dia harus mendekatinya dan membuat permohonan (Br. 6.4.6).

2. Jika diatidak maumengabulkankeinginannya, dia harus membeli (hadiah). Jika dia masih tegar, dia harus memukulnya (bukan sebagai lawan) dengan tongkat atau dengan tangan (dalam bentuk rayuan) dan mengalahkannya, dengan mengucapkan mantra berikut, "Aku mengambil kekuatan tubuhmu." Kemudian dia menjadi lemah tanpa kekuatan (Br. 6.4.7).

3. Jika dia setuju, dia harus berkata, "Melalui air mani (sperma) saya, saya akan mengirimkan 
kemuliaan saya kepada Anda." Lalu keduanya bersinar dengan kuat (Br. 6.4.8).

\section{II.6 Cara Bercinta}

Jayaram juga menguraikan bahwa sebagaimana terbukti dari mantram ini (Br. 6.4.9), ketika bercinta, pria membacakan mantra untuk mempengaruhii pasangan mereka dan melibatkan mereka dalam hubungan seks aktif. Namun, tujuan utamanya adalah prokreasi (menjadi ayah). Jika seseorang ingin berhubungan seks dengan seorang wanita berpikir bahwa dia dapat menikmati cintanya, maka ia dapat memeluknya tubuhnya, menekan mulutnya ke arahnya, membelai tubuhnya, pria itu harus melafalkan mantra yang artinya, "Kamu, yang dilahirkan dari setiap anggota tubuh saya, diciptakan dari hatiku, kau adalah esensi tubuhku. Semoga dia menjadi tergila-gila padaku seakan dia telah terkena panah beracun (asmara)."

\section{II.7 Seorang Pria dan Wanita Hindu Mesti Memiliki Pengetahuan Seksual}

Pustaka Niti Sataka sloka 5 (dalam Somvir, 2003:38) menytakan: "Putra yang baik adalah mereka yang dapat membahagiakan orangtuanya dengan tingkah laku yang baik; istri yang baik adalah istri yang menginginkan kemakmuran dan kesejahteraan suaminya; sahabat yang baik adalah sahabat yang selalu ada pada saat suka maupun duka; ketiga hal itu hanya didapatkan oleh mereka yang memiliki karma utama (perbuatan-perbutan yang mulia). Intisari dari sloka ini dari sloka 5 Niti Sataka ini hubungannya dengan tema seksual adalah bahwa good partnerships antara wanita dan pria. Sesungguhnya dunia ini hanya miliki dua orang saja, yaitu miliki laki-laki dan perempuan; karena itu jika pria dan wanita sedang kasmaran, maka dunia ini merasa miliki mereka berdua, semuanya merasa indah bahkan tai kambing terasa coklat.

Kasmaran yang baik seharusnya bukan sebagai pelampiasan nafsu, kasmaran atau trisna harus menjadi persembahan kepada Tuhan dengan kata lain seharusnya hubungan seksual itu merupakan persembahan kepada Tuhan. Caranya adalah melakukan hubungan seksual sesuai yang diatur dalam sastra agama. Pustakan suci Manava Dharmasastra III.45-48 terdapat aturan pria kapan dan bagaimana cara menggauli istri. Pada Manava Dharmasastra III.45 dinyatakan bahwa seorang suami untuk tujuan membahagiakan istrinya ia boleh menggauli istrinya kapan saja, kecuali hari parvani (sehari sebelum Purnama dan sehari sebelum Tilem) dan seorang suami harus puas hanya dengan istrinya seorang. Pada Manava Dharmasastra III.7 dinyatakan bahwa pada hari ke 1, 2, 3, 4, 11, 13 setelah haid dilarang menggauli istri. Pada Manava Dharmasastra III.48-49 hubungan seksual suami-istri yang diatur waktunya sedemikian rupa dapat memprogram kelahiran bayi laki-laki atau perempuan.

\section{II.8 Pengetahuan Seksual dalam Upaniṣad}

Sebagaimana dinyatakan di atas bahwa ada banyak penulis dan peneliti Upaniṣad, baik sebagai orang suci atau seorang intelektual akademikus, di antaranya Swami Samvidananda Saraswati (2008) dengan judul Essence of The Upaniṣad; Swami Gambhirananda (2012) dengan judul Eight Upanișads with the 
Comentary of Sankaracarya Vol.I,II; kelompok para ahli editor K1. Joshi, O.N. Bimali, dan Bindya Trivedi (2007) dengan judul 112 Upanișad (Sanskrit Text, English Translation, An Exhaustive Introduction and Index of Verses); dll, maka dalam artikel ini dipilih pustaka Upaniṣad karya Prof. S. Radhakrishnan (rpt.2008).

\section{Brahmacarya bukan berarti} menghancurkan seks. Tidak ada jurang antara yang lahiriah dengan jiwa, tetapi hanya antara lahiriah yang jatuh dan yang berubah. Para pemikir di Timur berpendapat bahwa bibit yang terdapat di dalam tubuh lelaki maupun wanita adalah bertujuan untuk menciptakan tubuh yang mana jiwa yang lain akan menjadi mempunyai tubuh. Ketika hal ini dikendalikan, brahmacarya akan membantu segala macam pekerjaan kreatif yang bisa digambarkan. Ketika bibit ini dibuang percuma dalam permainan seks yang berlebihan, tubuh menjadi lemah dan lumpuh, muka berkerut, mata tidak bersinar, pendengaran terganggu dan otak tidak aktif bekerja. Bila brahmacarya dijalankan maka tubuh fisik akan tetap muda dan cantik, otak tajam dan siaga, seluruh pengungkapan fisik akan merupakan bayangan dan kemiripin dengan Tuhan (Radhakrishnan, 2008:74).

Pada pustaka Upaniṣad ada banyak bramana atau sloka menguraikan hakikat wanita dan hubungannya antara wanita dan pria sebagai wujud yajna atau persembahan kehadapan Tuhan Yang Maha Pencipta. Pada artikel dipilih Brhad'aranyaka Upaniṣad VI.4.1-28 (dalam Radhakrishnan, 2008:243-251), karena dalam pusata Upaniṣad bagian Brahamana keempat dengan jelas menunjukkan bahwa hubungan seksual antara wanita dan pria adalah aktivitas yajna atau persembahan suci, bukan hanya sebagai pelampiasan nafsu biologis yang sebagian orang awam meanggapnya sebagai hal yang manusiawi.

Oleh sebab itu, seseorang yang ingin menjadi orang baik dan ingin memiliki keturunan yang baik, maka ia harus mengikuti aturan religius. Hubungan seksual yang dilakukan dengan spirit kedewataan yang luhur dan suci akan menghasilkan energi suci dan juga akan melahirkan anak-anak yang suputra; sebaliknya hubungan seksual yang didorong dengan spirit nafsu raksasa, maka akan menciptakan energy negative dan akan melahirkan manusia-manusia raksasa. Kekacauan, kebrutanan, trageditragedi kemanusiaan, emosi masyarakat yang meluap-luap seakan ingin saling membinasakan satu dengan yang lainnya, kakek mencabuli cucu, cucu mencabuli nenek, guru mencabuli murid dan murid mencabuli guru; manusia berhubungan seksual dengan binatang, dll. Jika semua peristiwa itu diteliti dengan saksama, maka akan diperoleh bahwa semua generasi yang bruta tanpa penguasaan emosi lahir dari hubungan seksual para orangtuanya dengan tidak mengikuti petunjuk agama. Masyarakat yang memiliki emosi sangat tinggi dan tidak toleran tumbuh dari masyarakat yang tidak mensucikan hubungan seksual.

\section{II.9 Pengetahuan Seksual dalam Pustaka Brhad'aranyaka Upaniṣad VI.4.1-28}

Pustaka Bṛhad'aranyaka Upanișad VI Brahmana 4.1-28 menguraikan tentang hakikat atau hal ikhwal pendidikan seksual sebagai wujud persembahan sebagaimana diuraikan dalam 28 
mantra Bṛhad'aranyaka Upanișad sebagai berikut: Eṣāì vai bhūtānāim pṛthivì rasah, prthivyā āpaḥ, apām oṣadhayaḥ, oṣadhīnām puṣpāṇi, puṣpaṇām phalāni, phalānāim puruṣaḥ, purușasya retạ (Bṛhad'aranyaka Upanișad VI.4.1).m'Bumi sesungguhnya adalah inti dari semua makhluk ini; inti bumi adalah air; inti air adalah tumbuhan; inti tumbuhan adalah kembangnya; inti kembang adalah buah; inti buah adalah manusia; inti manusia adalah air mani' (Mantik, 2008:243).

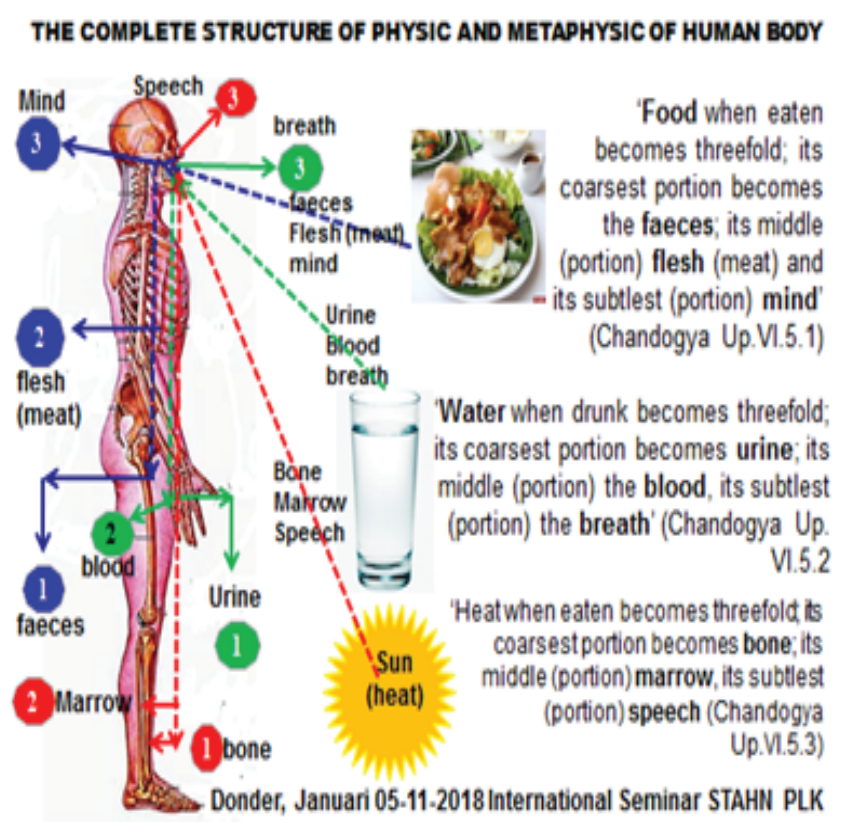

Mantra ini memberikan informasi bahwa kualitas sperma atau air mani yang akan menjadi unsur menentukan lahirnya generasi baru yang berkualitas ditentukan oleh kualitas sperma. Makanan berkualitas satvik menentukan kualitas sperma yang satvik, hal ini relevan dengan uraian Chandogya Upanișad VI.5.1-3 sebagaimana dinyatakan bahwa: 'Food when eaten becomes threefold; its coarsest portion becomes the faeces; its middle (portion) flesh (meat) and its subtlest (portion) mind' (Chandogya Upaniṣad VI.5.1) 'Water when drunk becomes threefold; its coarsest portion becomes urine; its middle (portion) the blood, its subtlest (portion) the breath' (Chandogya Upaniṣad VI.5.2 'Heat when eaten becomes threefold; its coarsest portion becomes bone; its middle (portion) marrow, its subtlest (portion) speech (Chandogya Up.VI.5.3). Sloka-sloka di atas menunjukkan bahwa makanan yang dimakan 1/3 menjadi kotoran yang dibuang, 1/3 menjadi pembentuk daging atau tubuh, dan 1/3nya lagi menjadi makanan otak atau menjadikan otak berfungsi; air yang diminum $1 / 3$ menjadi urine yang dibuang, 1/3 menjadi darah, dan 1/3-nya lagi menjadikan pernafasan berfungsi; energi panas yang masuk ke dalam tubuh, 1/3 akan menjadi tulang, 1/3 menjadi sumsum, dan 1/3-nya lagi menjadikan alat bicara berfungsi. Uraian ini mengingatkan kepada kisah Rsi Bhisma dan Rsi Drona, serta Karna yang diberikan makanan-makanan atau gaji dari hasil adharma, sehingga ketiganya tidak mampu memputuskan sesuatu secara benar pada saat pecah perang besar Bharata-yudha (Donder, 2018). Mantra berikut menguraikan:

sa ha prajā-patir ìkṣāim cakre: hanta, asmi pratiṣthāim kalpayānīti; sa striyam saṣ̣je: tāì srṣțvādha upāsta; tasmāt striyam adha upāsìta, sa etaì prāncaì grāvānam àtmana eva samudapārayat, tenainām abhyaș̣jat (Bṛhad'aranyaka Upaniṣad VI.4.2) 'Dan Prajā-pati berpikir sesaat dalam diri-Nya: dan kemudian berkata: 'Kesinilah akan $\mathrm{Ku}$ buatkan dasar yang kokoh untuknya (Dewi Satarupa).' Begitulah Ia (Prajapati) menciptakan perempuan. Setelah menciptakannya, Dia menempatkannya di bawah. Karena itulah 
setiap pria harus menghormati perempuan (dalam hubungan seksual) menempatkan wanita di bawah. Dia kemudian menuangkan (benih) yang ada pada diri-Nya sendiri sesuatu yang membuat bayangan-Nya. Melalui hal itu Dia menghamilinya (Dewi Satarupa).

Tasyā vedir upasthah, lomāni barhiḥ, carmàdhiṣavane, samiddho madyatastau mușkau; sa yāvān ha vai vājapeyena yajamānasya loko bhavati (tāvān asyaloko bhavati), ya evaì vidvān adhopahāsam carati, àsām strịnāim sukrtam vṛnkte. atha ya idam avidvān adhopahāsam carati, āsya striyah sukrtam vrnjate (Bṛhad'aranyaka Upanișad VI.4.3) 'Bagian bawah (perempuan ini) adalah tempat pemujaan yajna; rambutnya rumput yajna, kulitnya pemeras soma, kedua bibir (labia) dari pukas (vulva-nya) adalah api yang di tengah. Sesungguhnya, seagung apa dunianya dia yang menjalankan yajna vājapeya (seagung itu pulalah dunia dia) yang mengerti hal ini, menjalankan hubungan kelamin; dia membawa kepada dirinya pahala baik dari perempuan itu kepada dirinya, tetapi dia yang tanpa mengerti hal ini menjalankan hubungan kelamin, pahala baik dari dirinya akan dibawa perempuannya (Mantik, 2008:243).

Radhakrishnan menambahkan bahwa mantra di atas ini menunjukkan hubungan yang dekat antara Atharva Veda dan Upaniṣadupanișad. Beberapa praktek yang terakhir ini dianggap sejalan dengan Atharva Veda. Di sana bahkan termasuk cara merayu supaya perempuan mau menyerahkan dirinya, cara untuk menghindari kehamilan, atau membawa kehamilan ketika diinginkan. Bahkan di sini motif pengetahuan kelihatan menguasai. Tindakan seksual dianggap sebagai bagian ritual, unsur mana disamakan dengan bagian tubuh perempuan. Kita diberitahu bahwa apabila seorang laki melakukan hubungan kelamin dengan pengetahuan ini, dia akan memenangkan duniayang samaagungnya denganyang diperoleh oleh dia yang menjalankan yajnavājapeya dan membawa untuk dirinya pahala yang ada pada perempuan; tetapi bila dia menjalankannya tanpa pengetahuan ini maka perempuan akan mengambil pahala laki-laki itu (Mantik, 2008).

Etadd ha sma vai tad vidvān uddālaka ărunir ăha; etadd ha sma vai tad vidvān nāko maudgalya ăha; etadd ha sma vai tad vidvān kumāra-hārita āha; bahavo maryā brāhmaṇāyanā nirindriyā visukrto'smāl lokāt prayanti; ya idam avidvāimso'dhopahāsam carantīti, bahu vā idam suptasya vā jāgrato vā retah skandati (Bṛhad'aranyaka Upanișad VI.4.4). 'Ini sesungguhnya adalah apa yang diketahui oleh Uddālaka Ārụ̣i ketika dia berkata: ini sesungguhnya adalah apa yang dikatakan oleh Nāka Maudgalya ketika dia berkata: ini sesungguhnya adalah apa yang diketahui oleh Kumarā-hārita ketika dia berkata banyak manusia yang fana, keturunan brāhmaṇa, meninggalkan dunia ini menjadi wanita dan tanpa manfaat, yaitu mereka yang melakukan tindakan seksual tanpa mengerti hal ini. Apabila bahkan sedemikian banyak air mani yang dikeluarkan oleh seseorang yang tidur atau terjaga' (Mantik, 2008:244).

Tad abhimrśet, anu vā mantrayeta: yan 
me'dya retah prthivìm askāntsìt, yad oṣadhìr apy asarat, yad apah. idam ahaì tad reta àdade, punar mām aitu indriyam, punas tejah, punar bhagah. punar agnir dhiṣnyāh yathāsthānaì kalpantām. ity anāmikāinguștābhyām ādāya, antareṇa stanau vā bruvau vā nimrjyāt (Bṛhad'aranyaka Upaniṣad VI.4.5).' Kemudian dia harus merabanya atau tanpa merabanya sambil berucap: Kapan saja air mani-ku terpercik ke bumi, kapan saja mengalir ke pohon, ke air, aku menuntut kembali air mani ini, semoga kekuatan kembali lagi kepadaku. Semoga api dan tempat pemujaan ditemukan lagi ditempatnya semula; setelah mengatakan hal ini dia harus mengambil hal ini dengan jari manisnya menggosoknya diantara buah dadanya atau diantara alisnya' (Mantik, 2008:244).

Atha yady udaka àtmānam paśyet, tad abhimantrayeta: mayi teja indriyam yaśo dravinaim sukrtam iti-śrīr ha vā eșā strịnāim yan malodvāsāḥ. tasmān malodvāsasam yaśasvinìm abhikramyopamantrayeta (Bṛhad'aranyaka Upaniṣad VI.4.6).'Sekarang, apabila seseorang melihat bayangannya pada air, dia harus mengucap wirama berikut : Semoga Tuhan memberkahi aku dengan sinar, kekuatan, kemashuran, kekayaan dan gelar. Ini sesungguhnya adalah kecantikan diantara wanita, ketika dia menanggalkan bajunya yang tidak bersih. Karena itulah ketika dia menanggalkan bajunya yang tidak bersih dan dia kelihatan cantik, dia harus mendekatinya dan berbicara dengannya (Mantik, 2008:243).

Sā ced asmai na dadyāt, kāmam enām avakrīnīyāt; sa ced asmai naiva dadyāt, kāmam enām yaștyā vā pāninina vopahat-yātikrāmet, indriyeṇa te yaśas ā yaśa ādade, ity ayaśa eva bhavati (Bṛhad'aranyaka Upaniṣad VI.4.7).'

Bila perempuan itu tidak memenuhi keinginannya, dia harus memberikannya hadiah-hadiah. Bila dia tetap tidak memenuhi keinginannya, dia harus dipukul dengan tongkat atau tangan dan melakukannya dengan kelaki-lakian penuh dan mengatakannya: Aku mengambil kemuliaanmu' . Dengan demikian dia akan kehilangan kemuliaannya. sā ced asmai dadhyāt: indriyeṇa te yaśayā yaśa ādadhāmi iti; yaśasvināv eva bhavatah (Brhad'aranyaka Upaniṣad VI.4.8) 'Bila perempuan itu memenuhi keinginannya, dia berkata: 'Dengan kekuatan dan kemuliaan,' 'Aku memberikanmu kemuliaan.' Demikianlah keduanya menjadi mulia.

Sa yām icchet, kāmayeta meti, tasyām artham niṣthāya, mukhena mukham samdhāya,

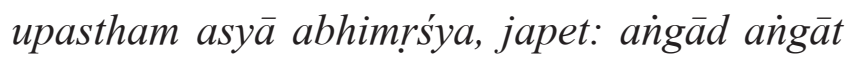
sambhavasi, hrdayād adhijāyase sa tvam angakaṣāyo'si: digdha-viddhām iva mādaya imām amūंm mayi iti (Bṛhad'aranyaka Upaniṣad VI.4.9). 'Bila seseorang menginginkan seorang perempuan dengan pikiran mudah-mudahan perempuan itu menikmati cinta denganku, setelah memasukkan barangnya kepadanya, mencium mulutnya, menekan bagian bawahnya, dia harus mengucap: 'Engkau yang berasal dari setiap sendi tubuh, yang meloncat dari hati, engkau adalah sarinya anggota tubuh. Mabukkanlah perempuan yang ada padaku ini seolah dia ditembus panah beracun.'

Atha yām icchet: na garbhai் dadhìteti, tasyām arthum niṣthāya, mukhena mukham 
samdhāya abhiprānyyāpānyāt, indriyeṇa te retasā reta ādada iti; aretā eva bhavati (Bṛhad'aranyaka Upanișad VI.4.10). 'Sekarang perempuan yang diinginkan seseorang dengan pikiran: 'semoga dia tidak hamil,' setelah membenamkan anggotanya kepadanya, menyatukan mulut dengan mulut, dia haruslah pertama-tama menarik nafas dan kemudian mengeluarkannya dan berkata: 'dengan kekuatan, dengan air mani, aku meminta kembali air mani darimu. 'Demikianlah perempuan akan keluar tanpa air mani'. Atha yām icchet: garbhaì dadhìteti, tasyām arthaì nișthāya, mukhena mukhai் samdhāya apānyābhiprānyāt, indriyeña te retasā reta ādadhāmi, ity, garbhiny eva bhavati. (Bṛhad'aranyaka Upanișad VI.4.11). 'Sekarang perempuan yang diinginkan seseorang dengan pikiran: 'semoga dia hamil'; setelah membenamkan anggotanya kepadanya, menyatukan mulut dengan mulut dia pertamatama harus mengeluarkan nafas dan kemudian menariknya dan berkata: 'dengan kekuatan, dengan air mani, aku menempatkan air mani padamu.' Kemudian dia akan menjadi hamil.

Atha yasya jāyāyai jārah syāt, taim ced dvișyāt āmapātre'gnim upasamādhāya, pratilomaì śarabarhis tīrtvā, tasminn etāh śarabhrștīh paratilomāh sarpiṣāktā juhuyāt; mama samiddhe'haușīh, prāṇāpānau na $\bar{a}$ dadeas $\bar{a} v$ iti. mama samiddhe'haușīh, putra-paśúms ta àdadeas $\bar{a} v$ iti. mama samiddhe'haușịh iștāasukrte ta ädade, as āv iti. mama samiddhe 'haușìh àśā-parākāśau ta adade asāv iti. sa vā eșa nirindriyo visukrto 'smāl lokāt praiti, yam evam-vid brāhmanah śapati. tasmāt evam-vit śrotriyasya dāreṇa nopahāṣam icchet, uta hy evam-vit paro bhavati (Brhad'aranyaka Upanișad VI.4.12). 'Bila istri seorang laki-laki mempunyai kekasih dan dia membenci dan ingin melukainya, dia harus membuat api pada periuk tanah lempung, memaparkan selapis rumput-panah dalam urutan yang berlawanan membiarkan dia mempersembahkan korbannya pada urutan yang berlawanan rumput-panah ini yang dibasahi dengan minyak ghee, sambil mengatakan: "Engkau telah dikorbankan dalam apiku, kuambil nafas-ke luar (prana) dan nafas-ke dalam-mu (apana). Engkau telah dikorbankan dalam apiku, kuambil anak-anakmu dan ternakmu. Engkau telah dikorbankan dalam apiku, kuambil yajna-mu dan perbuatanmu yang mulia. Engkau telah dikorbankan dalam apiku, kuambil harapanmu dan cita-citamu. Nantinya dia meninggalkan dunia ini dalam keadaan impoten dan tanpa kemuliaan, yang kalau seseorang brāhmaṇa mengetahuinya akan mengutuknya. Karena itu seseorang janganlah mencoba untuk main gila dengan istri seseorang yang terpelajar dalam susastra Veda dan yang mengerti hal ini akan menjadi terpandang'

Atha yasya jāyām ārtavaì vindet, try aham kamse na pibet ahata-vāsāh; nainām vrșalah na vrṣaly upahanyāt, trirātrānta āplutya vrìhin avaghātayet (Bṛhad'aranyaka Upanișad VI.4.13). 'Sekarang bila datang bulan menimpa sang istri maka selama 3 hari dia tidak boleh minum dari cangkir perunggu dan tidak juga mengenakan baju baru. Dilarang menjamah dia, baik oleh orang perempuan dengan kasta rendah maupun lelaki dari kasta rendah. Pada akhir malam ketiga setelah mandi, dia harus menumbuk beras'. Sa ya icchet, 
putro me śuklo jāyeta, vedam anubruvìta, sarvam āyur iyād iti, kṣīraudanam pācayitvā sarpiṣmantam aśnīyātām; ìśvarau janayita vai (Bṛhad'aranyaka Upaniṣad VI.4.14). 'Bila dia menginginkan putranya lahir dengan kulit terang; menginginkan agar kelak dia belajar Veda bahwa dia akan mencapai umur panjang, mereka mesti memasak nasi dengan susu dan menyantapnya bersama ghee, maka dengan cara demikian mereka bisa memperolehnya'.

Atha ya icchet, putro me kapilah pingalo jāyeta, dvau vedāv anubruvita, sarvam $\bar{a} y u r$ iyād iti, dadhy-odanaì pācayitvā sarpiṣmantam aśnīyātām; ìśvarau janayita vai. (Bṛhad'aranyaka Upaniṣad VI.4.15). 'Sekarang bila seseorang mengharapkan putranya lahir dengan kulit coklat menginginkan agar kelak dia belajar Veda, mencapai umur panjang, mereka harus memasak nasi dalam paneer menyantapnya bersama ghee, kemudian barulah mereka akan memperolehnya' (Brhad'aranyaka Upanișad VI.4.15). Atha ya icchet, putro me śyāmo lohitākṣo jāyeta, trīn vedān anubruvìta, sarvam āyur iyād iti, udodanam pācayitvā sarpiṣmantam aśnīyātām; ìśvarau janayita vai (Bṛhad'aranyaka Upaniṣad VI.4.16). 'Sekarang bila seseorang menginginkan putranya dilahirkan dengan kulit gelap dan mata merah, menginginkan agar kelak dia belajar ketiga $V e d a$, mencapai umur panjang, mereka harus memasak nasi dalam air dan memakannya dengan ghee dan kemudian barulah dia akan mendapatkannya.

Atha ya icchet, duhitā me paṇditā jāyeta, sarvam āyur iyād iti, tilodanaì pācayitvā sarpiṣmantam aśnīyātām; ìśvarau janayita vai (Bṛhad'aranyaka Upaniṣad VI.4.17). 'Sekarang bila seseorang menginginkan anak perempuannya terlahir, menjadi orang yang terpelajar, memperoleh umur panjang, mereka harus memasak nasi dengan wijen dan memakannya dengan ghee, kemudian barulah dia akan memperolehnya'. Atha ya icchet, putro me paṇdito vigìtaḥ, samitim-gamaḥ, śuśrūṣitām vācam bhāṣitā jāyeta, sarvān vedān anubruvīta, sarvam āyur iyād iti, māmsodanam pācayitvā sarpiṣmantam aśnīyātām, ìśvarau janayita vai, aukṣnena vārṣabheṇa vā (Bṛhad'aranyaka Upaniṣad VI.4.18).'Sekarang bila seseorang menginginkan seorang putra yang terpelajar, termashur, menjadi pemimpin, pembicara dengan kata-kata yang menarik, menginginkan agar kelak dia belajar Veda, mencapai umur panjang, mereka harus memasak nasi dengan daging dan memakannya dengan ghee, kemudian barulah mereka sanggup memperolehnya (daging angsa dan sapi).

Athābhiprātar eva sthālī-pākāvrtājyyam ceștitvā, sthālīpākasyopaghātaim juhoti: agnaye svāhā, anumataye svāhā, devāya savitre satyaprasavāya svāhā, iti; hutvā uddhrtya prāśnāti, prāśyetarasyāḥ prayacchati; prakṣālya pāṇī, udapātram pūrayitvā tenainām trir abhyukșati; uttișthāto viśvāvaso, anyām iccha prapūrvyām, saì jāyàm patyā saha,iti (Brhad'aranyaka Upaniṣad VI.4.19). 'Sekarang menjelang pagi, setelah mempersiapkan ghee sesuai dengan aturan sthālì-pāka, dia mengambil sthālì-pāka dan membuat persembahan sambil berkata: 'Pujian kepada api, pujian kepada Anumati, kepada gemerlapannya matahari, pujian kepada 
pencipta kebenaran'. Setelah selesai melakukan persembahan dia mengambil prasadam dan memakannya. Setelah memakannya dia memberikan sisanya kepada yang lain (istrinya). Setelah mencuci tangannya dan mengisi tempat air, dia memercikkan tiga kali kepada istrinya sambil berkata: 'Bangunlah dari sini, Viśvāvasu, carilah perempuan muda yang lain, seorang istri dengan suaminya.'

Athainām abhipadyate: amo'ham asmi, sā tvam; sā tvam asi, amo'ham; sāmāham asmi, rk vam; dyaur aham, prthivī tvam; tāv ehi samrabhāvahai, saha reto dadhāvahai pumse putrāya vittaye iti (Bṛhad'aranyaka Upanișad VI.4.20). 'Kemudian dia memeluknya sambil berkata; 'Aku adalah nafas-vital dan engkau adalah wicara; engkau wicara dan aku adalah nafas-vital. Aku adalah Sāman dan engkau Rg. Aku adalah surga dan engkau bumi. Kemarilah marilah kita berjalan bersama, marilah kita mencampur air mani sehingga kita akan mempunyai anak laki-laki'. Athāsyy $\bar{u} r \bar{u}$ vihāpayati: vijihìtāim dyāvāprthivī, iti tasyām artham niṣthāya, mukhena mukham samdhāya, trir enām anulomām anumārṣți. viṣnur yonim kalpayatu, tvaș̣ā rūpāṇi pimśatu āsincatu prajāpatih, dhātā garbhaì dadhātu te: garbham dhehi, sinīvāli; garbham dhehi, prthuștuke, garbhaì te aśvinau devau ädhattām puṣkarasrajau (Bṛhad'aranyaka Upaniṣad VI.4.21). 'Kemudian dia membuka kedua pahanya dan berkata: 'Bukalah kedua pahamu, Bumi dan Langit. Setelah memasukkan anggotanya kedalamnya, setelah mulut bertemu mulut, dia menekannyatigakali,ketikarambutsedangrebah, sambil berkata: 'Semoga Viṣnu mempersiapkan kandungannya. Semoga Tvaṣtr membuat bentuknya. Semoga Prajā-patimenuangkannya. Semoga Dhātṛ menempatkan bibitnya untukmu. Wahai Sin̄̄vāli, berikanlah bibitnya, wahai gadis berambut tebal berombak. Semoga kedua Aśvin yang bermahkota padma menempatkan bibitnya.'

Hiraṇmaȳ̄ araṇi yābhyām nirmanthatām aśvinau; tam te garbham havāmahe daśame māsi sūtaye: yathāgni-garbhā prthivì, yathā dyaur indreṇa garbhiṇi vāyur diśām yathā garbhah, evam garbham dadhāmi te asāv iti (Bṛhad'aranyaka Upaniṣad VI.4.22). 'Kedua Aśvin memutar api dengan dua tongkat penggosok yang terbuat dari emas. Ini adalah bibit yang demikian sehingga kami memintanya untuk dibawa pada bulan kesepuluh. Seperti halnya bumi mengandung bibit api dan langit mengandung badai, seperti halnya udara adalah bibitnya mata angin, demikianlah aku menempatkan bibit padamu. Sosyantìm adbhir abhyukṣati; yathā vayuḥ puṣkarin̄ìm samingayati sarvatah evā te garbha ejatu sahāvaitu jarāyuṇā: indrasyāyam vrajah krtah sārgalah sapariśrayah, tam, indra, nirjahi garbheṇa sāvarāim saheti (Bṛhad'aranyaka Upanișad VI.4.23). 'Ketika dia sudah hampir melahirkan, sang suami memercikkan air kepadanya sambil berkata: 'Sama seperti angin menggoyang telaga teratai dari semua sisi begitulah semoga janinmu bergolak dan keluar bersama dengan bungkus luarnya. Bungkusan Indra ini telah dibuat dengan penutup disekelilingnya. Wahai Indra, buatlah dia keluar sesudah melahirkan bersama dengan bayinya. 
Jāte'gnim upasamādhāya, à்ka àdhāya kamise prṣad-ājyam samnīya, prṣadäjyasyopaghātam juhoti: asmin sahasram puṣyāsam edhamāmah sve grhe asyopasandyām mā chaitsìt prajayā ca paśubhiś ca, svāhā: mayi prānāàms tvayi manasā juhomi, svāhā: yat karmaṇātyarīricam, yad vā nyūmam ihākaram, agniṣtat sviṣtakrd vidvān, sviștam suhutam karotu nah; svāhā (Bṛhad'aranyaka Upanișad VI.4.24). 'Ketika seorang putra terlahir, setelah mempersiapkan apinya, setelah menaruh bayi pada pangkuannya, setelah menempatkan paneer dan ghee pada mangkok perunggu, dia membuat persembahan lagi dengan paneer dan ghee dan berkata: 'Semoga aku menambah dengan anak ini dan lebih subur seribu kali dalam rumahku. Semoga nasib baik tidak pernah meninggalkan dia dengan ternak dan keturunannya. Semoga. $\mathrm{Aku}$ mempersembahkan kepadamu secara mental, kekuatan vital yang ada pada diriku. Apapun dalam perbuatanmu aku melakukannya terlalu banyak atau terlalu sedikit disini, semoga Agni Yang Maha Tahu, Yang Welas Asih, membuat hal ini pantas dan baik untuk kami. Semoga'.

Athāsya dakṣiṇam karṇam abhinidhāya: vāg vāg iti trih, atha dadhi madhu ghrtam samin̄ya anantarhitena jāta-ūpeṇa prāśayati; bhūs te dadhāmi, bhuvas te dadhāmi, svas te dadhāmi bhūr bhuvah svah sarvaì tvayi dadhāmìti (Bṛhad'aranyaka Upaniṣad VI.4.25). 'Kemudian menaruh mulutnya dekat telinga kanan sang bayi, dia berkata tiga kali, bicaralah, bicaralah, bicaralah. Kemudian dengan mencampur paneer, madu dan ghee, dia memberinya makan dengan sendok emas yang tidak diletakkan/dimasukkan dalam mulut dan berkata: 'Kutempatkan bumi padamu, kutempatan angkasa padamu, kutempatkan langit padamu. Kutempatkan semuanya padamu, bumi, langit, angkasa.' Athāsya nāma karoti: vedo'sīti; tad asya tad guhyam eva nāma bhavati (Brhad'aranyaka Upaniṣad VI.4.26). 'Kemudian dia memberikannya nama dan berkata: 'Engkau adalah Veda.' Demikianlah hal ini menjadi nama rahasianya.

Athainaì mātre pradāya stanaì prayacchati; yas te stanah śaśayo yo mayobhūh, yo ratnadhā vasuvid yạ sudatrah, yena viśvā puṣyasi vāryāṇi, sarasvatī, tam iha dhātave kah (Bṛhad'aranyaka Upaniṣad VI.4.27). 'Kemudian dia memberikannya kepada ibunya dan memberikannya air susunya dan berkata: Susu-mu yang segar dan menyehatkan, kaya, berlimpah, dermawan, yang engkau berikan sebagai makanan bagi makhluk yang pantas, Sarasvati, berikanlah dia disini (kepada istriku untuk anakku) untuk menikmatinya. 28. Athāsya mātaram abhimantrayate: ilāsi maitrāvarun̄ī; vīre vīram ajījanat, sā tvaì vìravatì bhava, yāsmān vìravato'karat. iti. taì vā etam āhuḥ; atipitā batābhūh, atipitāmaho batābhūḥ. paramāim bata kāṣthām prāpat, śriya yaśas ā brahma-varcasena, ya evam vido brāhmaṇasya putro jāyata iti (Bṛhad'aranyaka Upaniṣad VI.4.3). 'Kemudian dia berkata kepada sang ibu (dari bayi): 'Engkau adalah Ilā, keturunan Mitrā dan Varuṇa. Karena kau adalah seorang pahlawan wanita, engkau melahirkan seorang pahlawan. Engkau yang telah memberikan kami seorang pahlawan sebagai putra, semoga engkau akan menjadi ibu 
dari banyak pahlawan.' Tentang putra seperti ini mereka mengatakan: 'Engkau telah melampaui ayahmu; engkau telah melampaui kakekmu.' Sesungguhnya dia telah mencapai tempat tertinggi dalam kemakmuran, kemashuran dan gemerlapannya semangat, yang telah terlahir sebagai putra seorang Brāhmaṇa, yang mengerti hal ini (Radhakrishnan, 2008).

Berdasarkan uraia panjang lebar di atas dapat disimpulkan bahwa aktivitas seksual harus dilihat dalam arti swadharma suci yang dilaksanakan dalam bentuk hubugan intim atau hubungan mesra yang indah dan dipelihara secara terus-menerus antara pasangan suamiistri tanpa mengenal jemu. Kondisi itu perlu diciptakan semata-mata agar dalam hubungan seks suami-istri tercipta nuansa yang indah yang vibrasinya dapat dirasa oleh janin atau cabang bayi. Sehingga lahir bayi-bayi yang suputra sebagaimana dinyatakan dalam pustaka Cāṇakya Cānakya Cāṇakya Nītī Śāstra khususnya dalam sloka-sloka II.4; III.14; 16, 17, IV.6,7, (Darmayasa, 2014). Melalui cara pandangan yang benar terhadap seksualitas, maka kejahatan seksual semestinya tidak perlu terjadi.

\section{KESIMPULAN}

Sesuai dengan latar belakang, rumusan masalah studi pustaka, dan pembahasan, maka dapat disimpulkan sebagai berikut:

1. Teo-seksologi adalah bidang ilmu interdisipliner antara ilmu agama, terutama teologi dan psikologi serta kedokteran. Satu bidang ilmu interdisipliner yang mengaitkan secara sinergis antara beberapa disiplin ilmu filsafat, agama dan kedokteran guna memecahkan persoalan manusia yang kompleks.

Pegetahuan Teo-seksologi menjadi satu bagian penting dalam sistem pendidikan bagi para pemuda-pemudi dan dalam hal ini para pemuda-pemudi Hindu sebab, para pemudapemudi saat ini di kemudian hari diharapkan dapat menjadi orang tua yang dengan melahirkan para generasi yang berkualitas yang disebut sebagai generasi emas pada tahun 2045. Sebab, tepat pada tahun 2045 itu kemerdekaan Negara Republik Indonesia mencapai usia 100 tahun, yaitu tahun emas dan generasinya juga diharapkan memiliki kualitas seperti emas murni.

Jika para pemuda-pemudi saat, semasih dini sudah memiliki prilaku seksual yang tidak benar, menyimpang dari aturan-aturan agama, maka para pemuda-pemudi saat ini tidak dapat diharapkan akan melahirkan generasi yang berkualitas. Hubungan seksual yang liar yang mencirikan sifat raksasa, akan melahirkan generasi-generasi berkarakter raksasa. Melalui pembelajaran seksologi yang benar, maka seseorang akan memahami efek negatif dari hubungan seksual yang tidak sah.

Hubungan seksual yang liar dan brutal tidak mengindahkan nilai-nilai agama dan moral hingga menyebabkan kehamilan sebelum perkawinan hal menyebabkan adanya "perkawinan kecelakaan". Efek negatifnya akan lahir generasi-generasi kecelakaan 
metal. Melakukan aborsi atau menggugurkan kandungan karena hamil diluar perkawinan akan menyebabkan kerusakan kandungan yang berakibat tidak bisa hamil yang akan membawa dampak buruk pada perkawinan. Karena itulah, pengetahuan Teo-seksologi dipandang penting diajarkan kepada para pemuda-pemudi.

2. Metode, cara atau teknik pengetahuan seksologi itu diajarkan yaitu diberikan kepada para siswa dan mahasiswa di bangku sekolah atau bangku kuliah oleh para guru atau dosen yang memiliki kualifikasi dalam ilmu seksologi. Kualifikasi yang dimaksud bukan hanya pada penekanan kesehatan pada aspek fisik, tetapi juga pada aspek metafisik, spiritual atau yang bersifat religius. Oleh sebab itu, sekolah dan perguruan tinggi harus menyediakan guru atau dosen yang yang berkualifikasi dokter dan juga mendalami agama atau spiritual.

3. Implikasi pembelajaran seksologi secara benar dan tepat bagi para pemuda-pemudi Hindu akan memungkinkan terwujudnya para pemuda dan pemudi yang sehat lahir bantin dan memahami hakikat seksual sebagai swadharna atau kewajiban suci yang tidak boleh dilakukan secara sembarangan. Kesadaran mulia dari para pemuda dan pemudi menjadi jaminan akan lahirnya generasi-generasi mulia dan dengan lahirnya generasi-generasi yang mulia, maka akan terwujud masyarakat yang penuh dengan kedamaian.

\section{DAFTAR PUSTAKA}

Avadhuta, Acarya Gopalkrisnanda, 2006. Astavakra Samhita, Surabaya: Paramita

Aiyer, K. Narayanasvami, 2011. Thirty Upaniṣads (Edited by Madhu Khama, New Delhi: Tantra Foundation

Dister, Nico Syukur, 2007. Pengantar Teologi, Yogyakarta: Kanisius

Jalaluddin, H., 2002. Psikologi Agama, Jakarta: PT. Grafindo Perkasa

Krishna, Anand, 2006. Seksual QuotienMelampaui Kamasutra Memasuki Tantra, Jakarta: PT. One Earth Media

Pudja, G dan Tjok. Rai Sudharta, 2004. Mānava Dharmaśāstra (Manu Dharmaśāstra) atau Veda Smrti-Compendium Hukum Hindu, Surabaya: Paramita

Radhakrishnan, S. 2008. Upaniṣad-Upaniṣad Utama, Surabaya: Paramita

Sastri, Gaurinath, 2002. Rituas and Practice of Tantra I,II,III New Delhi: Cosmos Publication

Somvir, 2001. 108 Mutiara Veda Untuk Kehidupan Sehari-hari, Surabaya: Paramita Somvir, 2003. Niti Sataka - 100 Sloka Tentang Etika dan Moralitas Karya Bhartrihari, Denpasar: Program Magister Ilmu Agama dan Kebudayaan UNHI Bekerjasama dengan Penerbit Widya Dharma

Sudharta, Tjok. Rai, 1997. Manusia Hindu - 
Dari Kandungan Sampai Perkawinan, Denpasar: Yayasan Dharma Naradha

Watsyayana (Penj. Maswinara, 1997. Kama

Sutra, Surabaya: Paramita

\section{Website:}

(https://id.wikipedia.org/wiki/Seksologi, diunduh pada tanggal 25-07-2019).

Sex and Spirituality In the Upanișads;https:// www.hinduwebsite.com/Upanișads/essays/ sex-in-Upaniṣads.asp), 